\section{Asthmaforschung im humanisierten Mausmodell}

Die immunologische Forschung stützt sich in vielen Bereichen auf Tiermodelle. Speziesspezifische Unterschiede zwischen humanen und murinen Proteinstrukturen limitieren jedoch den Erkenntnisgewinn. Verschiedene Forschergruppen arbeiten daher an der Entwicklung humanisierter Mausmodelle.

In unterschiedlichen Projekten an der Universitäts-Hautklinik Mainz gelang es, humanisierte Mausmodelle als präklinische Testsysteme für neue immunotherapeutische Konzepte zu etablieren. Eine Methode sei dabei, durch Transfer humaner Stammzellen in immundefiziente neugeborene Mäuse das Heranreifen eines humanen Immunsystems in den adulten Tieren zu induzieren, erklärte Bettina Trinschek. Für die Humanisierung wurden aus Nabelschnurblut isolierte CD34+-hämatopoetische Stammzellen eingesetzt. Das Heranwachsen der humanen Immunzellen ist ein sehr individueller Prozess. Doch schon 16 Wochen post Transfer war ein Anwachsen humaner T-Zellen, B-Zellen, Monozyten und natürlicher Killerzellen nachweisbar und es kam zur Ausbildung von Thymus und Lymphknoten. Die Wissenschaftler konnten bereits die Funktionalität der humanen Immunzellen bestätigen: Durch Immunisierung der Mäuse konnten sowohl in vivo als auch ex vivo antigenspezifische Immunantworten nachgewiesen werden.

Eine Arbeitsgruppe um PD Dr. Iris Bellinghausen von der Universitäts-Hautklinik Mainz nutzte ein weiteres humanisiertes Mausmodell, um die Rolle des Chemokins CCL18 beim allergischen Asthma nicht nur in vitro, sondern auch in vivo zu überprüfen. Das vor allem von dendritischen Zellen (DC) freigevorgängen im Serum des Menschen stark erhöht. Da kein Homolog bei der Maus existiert, konnte die Funktion von CCL18 bislang in vivo nicht untersucht werden. In vitro inhibierte eine Zugabe von CCL18 zu CD4+-TZellen, die mit allergengepulsten reifen $D C$ stimuliert worden waren, die allergenspezifische Produktion von IL-4 und IL-5. Die Produktion von IFN- $\gamma$ und IL-10 sowie die T-ZellProliferation wurde dagegen nicht beeinflusst. setzte Chemokin ist bei vielen Entzündungs-
Für die in vivo-Untersuchungen wurden nun humane PBMC (,peripheral blood mononuclear cell") von hochgradig sensibilisierten allergischen Spendern zusammen mit dem entsprechenden Allergen in immundefiziente Mäuse injiziert. Wurde gleichzeitig auch CCL18 verabreicht, konnten allergische Atemwegsentzündungen nach intranasaler Allergenprovokation inhibiert werden. Zudem wurde die Rekrutierung von murinen Neutrophilen verringert. Diesen Daten zufolge scheint CCL18 eine wichtige Rolle bei der Immunregulation zu spielen und könnte ein therapeutisches Potenzial gegen allergische Atemwegsentzündungen besitzen, schlussfolgerte Bellinghausen.

Angelika Bauer-Delto

Trinschek B, Kubach J, Kurschus F, Jonuleit H. Humanized mice: effective preclinical model for studying complex human immune responses in vivo?

Bellinghausen I, Reuter S, Martin $\mathrm{H}$, Maxeiner J, Grabbe S, Taube C, Saloga J. Das Chemokin CCL18 inhibiert die allergische Atemwegsentzündung in einem humanisierten Mausmodell 